\title{
Emergency Overcrowding is Seasonal in a Hospital in Hainan Province, Southern China
}

jie jiao

Chinese PLA General Hospital

meng wang

Chinese PLA General Hospital

YONG-HONG LEI

Chinese PLA General Hospital

TAO WANG ( $\nabla 91698226 @ q q . c o m$ )

Chinese PLA General Hospital https://orcid.org/0000-0001-6427-8800

Research article

Keywords: Emergency overcrowding, Immigrant patients, Southern China

Posted Date: February 19th, 2020

DOI: https://doi.org/10.21203/rs.2.24008/v1

License: (c) (1) This work is licensed under a Creative Commons Attribution 4.0 International License.

Read Full License 


\section{Abstract}

\section{Background}

Emergency overcrowding is a serious problem for hospital staff in China. Immigrant patients caused emergency overcrowding in a hospital in southern China. However, the demographic characteristics of this population have not been determined.

\section{Methods}

Data on all emergency visitors, including patients who stayed in emergency department (ED) observation units or critical care units were collected and saved in an Excel sheet. Patient characteristics, including place of origin, type of disease, visiting time, and factors associated with prolonged stay in the ED, were analyzed.

Results

There were 141,024 emergency visitors in a 5-year interval, and only $24.0 \%$ of them were local residents. The number of patients was higher from November to March of next year. Immigrant patients usually had more commodity diseases than local residents. A total of 3,173 patients stayed in the ED observation unit or critical care unit in one-year interval. The number of patients in the ED and their LOS were higher from November 2017 to March 2018.

\section{Conclusions}

Emergency overcrowding in a hospital in southern China was seasonal and was caused by an increasing number of immigrants. Several patients stayed in the ED for a long time, especially those with special commodity diseases. Hospitals and the government should take measures to address the problems related to emergency overcrowding.

Key words: Emergency overcrowding; Immigrant patients; Southern China

\section{Background}

Overcrowding is a serious problem in developed countries $(1-4,17)$ and in China (5) and is primarily due to the large number of emergency visitors, shortage of emergency departments (EDs), nurses, and physicians, and limited access to health services. Overcrowding can lead to poor patient outcomes and increased length of stay (17). Some studies addressed these problems in China. A study (2017) evaluated 18 tertiary hospitals from Beijing and showed that 10 EDs had more than 100,000 patients annually (6). In each hospital, more than 11,000 patients stayed in the observation unit with a mean length of stay (LOS) of more than 5 days, and only $20 \%$ of them received inpatient care (6). More than 260,000 patients visited the ED of Shanghai Ruijin Hospital; of these, 2702 patients stayed in the ED for more than 48 hours from September 2009 to August 2010 (7), and (7). One study from Zhejiang province showed that 
access block (period from admission to the ED to admission to an inpatient unit) was a major contributor to prolonged LOS in the ED (8).

Our hospital is located in Sanya, a tropical city in Hainan Province in southern China. Many retired people from mainland migrate to Hainan in winter and, for this reason, are known as "snowbirds" (9-10). Seasonal migrations cause overcrowding in the ED of our hospital. The objective of this study is to investigate the epidemiology of ED visitors and factors affecting the LOS in the ED.

\section{Methods}

\section{Study setting}

This retrospective cohort study was conducted from August 2014 to July 2019 and was approved by the Institutional Review Board of our hospital. The study was conducted in an adult ED at a tertiary hospital with 660 inpatient beds and approximately 30,000 emergency patients annually. The ED has four subdepartments: outpatient clinic, observation unit (10 beds), critical care unit (10 beds), and ward (11 beds). One or two junior physicians work in each sub-department and one senior physician is on duty. Patients presenting to the ED were triaged by experienced nurses according to guidelines based on the Emergency Severity Index (ESI), which grouped patients into five triage levels (Table 1) (11). High-acuity patients (levels 1 and 2, and part of level 3 ) were referred to observation units or critical care units, whereas lowacuity patients (part of level 3 and levels 4 and 5) were referred to emergency outpatient clinics.

Table 1

Emergency Severity Index (ESI) triage algorithm.

\section{Level Clinical manifestations}

$5 \quad$ No resource is needed

$4 \quad$ Only one type of resource is needed

$3 \quad$ Many types of resources are needed*

2 High-risk situation, confusion, lethargy, severe pain, distress, disorientation, or critical vital signs

$1 \quad$ Immediate life-saving intervention is required

*Types of resources, including accessory examinations (laboratory analyses, electrocardiograms, radiological examinations), intravenous therapy, specialist consultations, or other procedures such as Foley catheterization.

\section{Study Design}

All the emergency visitor's data were collected and saved in an Excel sheet, including patient age, gender, place of origin, visiting month, and type of disease. The LOS in the ED observation unit or critical care unit 
was also calculated. Other factors that might favor a higher LOS, including age, visiting season, and type of disease, were analyzed.

Preliminary diagnosis was defined in each department according to the medical condition (medical diseases or surgical diseases). Medical diseases included respiratory, digestive, neurological, cardiovascular, endocrine and rheumatic, emergency, dermatological, and other conditions. Surgical diseases included mild trauma, orthopedic, urological, general surgery, and other conditions. Patient destination after discharge from the observation unit and critical care unit was divided into four groups: inpatient admission, transfer to other hospitals, death in the ED, and discharge after recovery or discharge without receiving advanced therapy.

\section{Statistical analysis}

Parametric data were presented as means standard deviation (SD) and frequencies. The categorical variables were compared using chi-square or Fisher's exact tests, where appropriate. Analysis of variance was performed to assess differences in the LOS in the ED among different groups and Student's ttest to analyze differences between two groups. A Cox proportional hazards model was constructed to evaluate the factors related to LOS. A two-tailed $\mathrm{P}<0.05$ was considered statistically significant. All analyses were performed using SPSS software version 19.0 (SPSS Inc., Chicago, IL, USA). The emergency visitor distribution map was created in Excel of Microsoft Office 2016.

\section{Results}

A total of 141, 024 patients visited the ED in a 5-year period. Of these, $24.0 \%$ lived in Hainan Province and the remaining patients $(107,178)$ lived in other provinces, including Heilongjiang $(13,130)$, Beijing (12,091), Sichuan (6,724), Jilin (6,362), Henan (6,316), Hebei (6,045), and Liaoning (5,739) (Fig. 1). The demographic characteristics of the study population in one-year interval (2017.08-2018.07) are shown in Table 2. The characteristics were different between Hainan and other provinces. The number of patients with older age, and respiratory diseases, was smaller and higher of mild trauma patients in Hainan Province (Fig. 4). 
Table 2

Characteristics of emergency department visitors in Hainan and other provinces in China from 2017.08 to 2018.07.

\begin{tabular}{|c|c|c|c|}
\hline & Hainan Province (N [\%]) & Other provinces ( $\mathrm{N}[\%])$ & Total \\
\hline & $7,333(100)$ & $24,938(100)$ & $32,271(100)$ \\
\hline Male & $5,215(71.1)$ & $18,032(72.3)$ & $23,247(72.0)$ \\
\hline \multicolumn{4}{|l|}{ Age $^{\star}$} \\
\hline$<45$ years & $4,900(66.8)$ & $12,780(51.2)$ & $17,680(54.8)$ \\
\hline $45-65$ years & $1,651(22.5)$ & $7,441(29.8)$ & $9,092(28.2)$ \\
\hline$>65$ years & $782(10.7)$ & $4,717(18.9)$ & $5,499(17.0)$ \\
\hline \multicolumn{4}{|l|}{ Primary diagnosis } \\
\hline \multicolumn{4}{|l|}{ Surgical diseases } \\
\hline Mild trauma* & $3,043(41.5)$ & $6,031(24.2)$ & $9,074(28.1)$ \\
\hline Urological & $217(3.0)$ & $962(3.9)$ & $1179(3.7)$ \\
\hline General surgery & $162(2.2)$ & $677(2.7)$ & $839(2.6)$ \\
\hline Orthopedic & $98(1.3)$ & $588(2.4)$ & $686(2.1)$ \\
\hline Others & $375(5.1)$ & $1117(4.5)$ & $2,178(6.7)$ \\
\hline \multicolumn{4}{|l|}{ Medical diseases } \\
\hline Respiratory* & $931(12.7)$ & $5,370(21.5)$ & $6,301(19.5)$ \\
\hline Digestive & $928(12.7)$ & $3,616(14.5)$ & $4,544(14.1)$ \\
\hline Cardiovascular* & $472(6.4)$ & $2,548(10.2)$ & $3,020(9.4)$ \\
\hline Neurological & $530(7.2)$ & $2143(8.6)$ & $2673(8.3)$ \\
\hline Emergency & $279(3.8)$ & $566(2.3)$ & $845(2.6)$ \\
\hline Dermatological & $107(1.5)$ & $591(2.4)$ & $698(2.2)$ \\
\hline Endocrine and rheumatic & $62(0.8)$ & $264(1.1)$ & $326(1.0)$ \\
\hline Others & $129(1.8)$ & $465(1.9)$ & $594(1.8)$ \\
\hline
\end{tabular}

The number of ED visitors varied by month and was higher from November to March of next year, especially in February. This trend was observed in all provinces, except in Hainan Province (Figs. 2 and 3). 
A total of 3,173 patients in one-year interval (2017.08-2018.07) were admitted to the observation unit or critical care unit, and the mean LOS was $1.2 \pm 2.0$ days. The patients with older age, respiratory diseases, digestive diseases, or severe conditions requiring ICU stay were admitted to the ED from November 2017 to March 2018 and usually stayed longer in the ED than the other groups (Table 2). The patients with acute myocadiac infarction requiring percutaneous coronary intervention $(\mathrm{PCl})$ had a significantly lower LOS in the ED. Only $50.2 \%$ of the patients visiting the emergency department observation units or critical care units received inpatient care. Moreover, a high percentage of patients with respiratory $(63.3 \%)$, digestive (63.4\%), cardiovascular (56.7\%), and neurological diseases (56.1\%) were not admitted to the ward. The number of patients visiting the ED and their LOS were higher from November 2017 to March 2018 (Fig. 4).

The risk factors assessed by multivariate Cox analysis are shown in Table 3. The factors associated with prolonged LOS in the ED were the month of admission (November to March) and the presence of respiratory or digestive diseases. The LOS was shorter in patients with acute myocadiac infarction needing $\mathrm{PCl}$. 
Table 3

Demographic characteristics and length of stay of 3,173 patients in emergency department observation units or critical care units from 2017.08 to 2018.07.

\begin{tabular}{|c|c|c|}
\hline & $N(\%)$ & $\begin{array}{l}\text { Length of stay (days } \\
\text { [SD]) }\end{array}$ \\
\hline & $\begin{array}{l}3,173 \\
(100)\end{array}$ & $1.2(2.0)$ \\
\hline \multicolumn{3}{|l|}{ Gender } \\
\hline Male & $\begin{array}{l}2,080 \\
(65.6)\end{array}$ & $1.2(2.1)$ \\
\hline Female & $\begin{array}{l}1093 \\
(34.4)\end{array}$ & $1.3(1.9)$ \\
\hline \multicolumn{3}{|l|}{ ESI score* } \\
\hline 3 & $\begin{array}{l}2,603 \\
(82.0)\end{array}$ & $1.2(1.7)$ \\
\hline 2 & $\begin{array}{l}494 \\
(15.6)\end{array}$ & $1.4(3.2)$ \\
\hline 1 & $76(2.4)$ & $0.5(0.9)$ \\
\hline \multicolumn{3}{|l|}{ Age* } \\
\hline$\leq 65$ years & $\begin{array}{l}1909 \\
(60.2)\end{array}$ & $1.0(2.2)$ \\
\hline$>65$ years & $\begin{array}{l}1264 \\
(39.8)\end{array}$ & $1.4(1.8)$ \\
\hline \multicolumn{3}{|c|}{ Month of admission to the ED* } \\
\hline April to October & $\begin{array}{l}1459 \\
(46.0)\end{array}$ & $0.9(1.6)$ \\
\hline November to March & $\begin{array}{l}1714 \\
(54.0)\end{array}$ & $1.4(2.3)$ \\
\hline \multicolumn{3}{|l|}{ Weekend admission* } \\
\hline No & $\begin{array}{l}2,276 \\
(71.7)\end{array}$ & $1.2(2.2)$ \\
\hline
\end{tabular}

${ }^{*} \mathrm{P}<0.05$, compared the length of stay in the emergency department observation unit and critical care unit.

ESI, Emergency Severity Index; PCl, percutaneous coronary intervention; ICU, intensive care unit; ED, emergency department 


\begin{tabular}{|c|c|c|}
\hline & $N(\%)$ & $\begin{array}{l}\text { Length of stay (days } \\
\text { [SD]) }\end{array}$ \\
\hline Yes & $\begin{array}{l}897 \\
(28.3)\end{array}$ & $1.1(1.5)$ \\
\hline \multicolumn{3}{|l|}{ Time of admission } \\
\hline 5:01 pm to 7:59 a.m. & $\begin{array}{l}1361 \\
(42.9)\end{array}$ & $1.1(2.2)$ \\
\hline 8:00 a.m. to 5:00 p.m. & $\begin{array}{l}1812 \\
(57.1)\end{array}$ & $1.3(1.9)$ \\
\hline \multicolumn{3}{|l|}{ Patient origin } \\
\hline Hainan Province & $\begin{array}{l}940 \\
(29.6)\end{array}$ & $1.1(2.7)$ \\
\hline Other provinces & $\begin{array}{l}2,233 \\
(70.4)\end{array}$ & $1.2(1.7)$ \\
\hline \multicolumn{3}{|l|}{ Primary diagnosis* } \\
\hline Cardiovascular & $\begin{array}{l}564 \\
(17.8)\end{array}$ & $0.9(1.3)$ \\
\hline Neurological & $\begin{array}{l}491 \\
(15.5)\end{array}$ & $1.1(1.7)$ \\
\hline Digestive & $\begin{array}{l}443 \\
(14.0)\end{array}$ & $1.6(2.2)$ \\
\hline Respiratory & $\begin{array}{l}323 \\
(10.2)\end{array}$ & $2.1(2.2)$ \\
\hline Other diseases & $230(7.2)$ & $0.9(1.4)$ \\
\hline General surgery & $220(6.9)$ & $1.2(1.8)$ \\
\hline Other surgical diseases & $218(6.9)$ & $0.7(1.0)$ \\
\hline Neurosurgical & $212(6.7)$ & $1.1(1.6)$ \\
\hline Emergency & $199(6.3)$ & $1.0(2.2)$ \\
\hline Acute myocardial infarction requiring $\mathrm{PCl}$ & $109(3.4)$ & $0.1(0.3)$ \\
\hline Severe conditions requiring ICU stay & $79(2.5)$ & $1.8(1.9)$ \\
\hline \multicolumn{3}{|l|}{ Patient destination after discharge } \\
\hline \multicolumn{3}{|c|}{$\begin{array}{l}* P<0.05 \text {, compared the length of stay in the emergency department observation unit and critical care } \\
\text { unit. }\end{array}$} \\
\hline \multicolumn{3}{|c|}{$\begin{array}{l}\text { ESI, Emergency Severity Index; } \mathrm{PCl} \text {, percutaneous coronary intervention; ICU, intensive care unit; ED, } \\
\text { emergency department }\end{array}$} \\
\hline
\end{tabular}




\begin{tabular}{|lll|}
\hline & $\mathbf{N}(\%)$ & \multicolumn{1}{l|}{$\begin{array}{l}\text { Length of stay (days } \\
\text { [SD] })\end{array}$} \\
\hline Death in the ED & $85(2.7)$ & $1.5(6.4)$ \\
\hline $\begin{array}{l}\text { Discharge after recovery or discharge without receiving } \\
\text { advanced therapy }\end{array}$ & $\begin{array}{l}1448 \\
(45.6)\end{array}$ & $1.2(2.1)$ \\
\hline $\begin{array}{l}\text { Inpatient admission } \\
\text { Transfer to other hospitals }\end{array}$ & $\begin{array}{l}1593 \\
(50.2)\end{array}$ & $1.2(1.5)$ \\
\hline $\begin{array}{l}* P<0.05, \text { compared the length of stay in the emergency department observation unit and critical care } \\
\text { unit. }\end{array}$ & $47(1.5)$ & $1.0(1.2)$ \\
\hline $\begin{array}{l}\text { ESI, Emergency Severity Index; PCl, percutaneous coronary intervention; ICU, intensive care unit; ED, } \\
\text { emergency department }\end{array}$ & \multicolumn{2}{l}{} \\
\hline
\end{tabular}


Table 4

Multivariate Cox regression analysis of factors associated with prolonged length of hospital stay among 3,173 high-acuity patients from 2017.08 to 2018.07 .

\begin{tabular}{|lll|}
\hline & P-value & OR (95\% Cl) \\
\hline & & \\
\hline Age $\leq 65$ years & 0.664 & $0.973(0.858-1.102)$ \\
\hline November to March & 0.000 & $1.273(1.120-1.447)$ \\
\hline Arrival in the ED between 8:00 a.m. and 5:00 a.m. & 0.035 & $0.869(0.763-0.991)$ \\
\hline ESI score =1 & Reference & \\
\hline 3 & 0.811 & $1.071(0.613-1.871)$ \\
\hline 2 & 0.002 & $0.758(0.638-0.901)$ \\
\hline Other medical diseases & Reference & \\
\hline Respiratory & 0.000 & $1.523(1.239-1.872)$ \\
\hline Emergency & 0.686 & $0.921(0.619-1.372)$ \\
\hline General surgery & 0.423 & $0.866(0.608-1.233)$ \\
\hline Neurological & 0.884 & $0.985(0.805-1.205)$ \\
\hline Neurosurgical & 0.609 & $1.079(0.807-1.443)$ \\
\hline Digestive & 0.004 & $1.341(1.095-1.641)$ \\
\hline Severe conditions requiring ICU stay & 0.148 & $0.741(0.494-1.112)$ \\
\hline Other surgical diseases & 0.252 & $1.272(0.843-1.92)$ \\
\hline Acute myocardial infarction requiring PCI & 0.162 & $0.369(0.091-1.493)$ \\
\hline Cardiovascular & 0.913 & $0.988(0.796-1.226)$ \\
\hline ESI, Emergency Severity Index; PCl, percutaneous coronary intervention; ICU, intensive care unit \\
\hline
\end{tabular}

\section{Discussion}

To our knowledge, this study is the first to evaluate emergency crowding by immigrants in southern China. The number of patients visiting the ED and their LOS were higher from November to March of next year. The demographic characteristics were different between local and immigrant patients.

In recent years, because of air pollution and severe weather, a large number of retired people migrate to the southern coast in warmer months $(9-10)$. Hainan Province is the most popular destination and 
attracted a large number of immigrants after 2009 (9-10). There were more than one million immigrants in Hainan Province in 2015, which was double the number in 2010 (9-10).

The period with the highest number of patients-November to March of next year-was designated the "medical boom season" by hospital staff. The months from November to April are often the coldest in mainland China, especially in northeast China. Our sample included many people from the north and northeast, including Heilongjiang, Beijing, Jilin, and Liaoning. Previous studies showed that many retired people, especially those with chronic diseases, migrated from these provinces to Hainan $(9-10,12,14)$. It has been reported that the good weather conditions in Hainan can improve stroke recovery, blood pressure, and chronic conditions, including pulmonary diseases (12-16). This fact could explain why relatively more patients with respiratory and cardiovascular diseases visited the ED in Hainan.

Emergency crowding in our hospital was not worse than the problem reported in larger cities in China, including Beijing, Shanghai, and Hangzhou (6-8). The mean LOS in the ED was 1.2 days, and only 50\% of the patients visiting this department received inpatient care. However, in Beijing, some patients stayed more than 5 days in the observation room, and only approximately $10 \%$ could wait for admission. In Shanghai, $12 \%$ were admitted to hospital wards, and some patients had to stay in the ED for extended periods, even more than 1 month. Similar results were found in Zhejiang. The problem of emergency overcrowding in China seems to be worse than in other countries. In Australia and the United Kingdom, the threshold of access block is 8 and 4 hours, respectively $(3,4)$.

The number of patients with respiratory, digestive, or cardiovascular diseases who were not admitted to the ward and had to spend a long time in the ED was higher than that of patients with other conditions. This result may be due to the limited capacity of specialized wards and other factors. Previous studies showed that specialized wards refused to admit patients with multiple organ dysfunction syndrome (68). Our results indicated that patients requiring emergency operations were transferred from the resuscitation room faster than other patients, and this may be because the surgical patients in our hospital were given priority to inpatient care.

The present study makes a significant contribution to the problem of emergency overcrowding. In the "medical boom season," hospitals need to hire additional staff and provide more ward beds, and the government should take measures to improve local hospitals' capacity to serve for more patients. The present study has limitations. First, this study was performed in a single center and, therefore, did not reflect the situation in the entire province. Second, data were incomplete because we did not determine the distances traveled by migrants and commodity factors affecting the long stay in the ED. The patients discharged from hospital after recovery and those discharged without receiving advanced therapy were not distinguished.

\section{Conclusions}

The results indicated that emergency overcrowding in a hospital in southern China was seasonal and was caused by an increasing number of migrants. Several patients had to stay in the ED for a long time, 
especially those with special commodity diseases. Hospitals should take appropriate measures to confront problems related to emergency overcrowding.

\section{Abbreviations}

ED

Emergency Department

LOS

Length of Stay

ESI

Emergency Severity Index

SD

Standard Deviation

$\mathrm{PCl}$

Percutaneous Coronary Intervention

\section{Declarations}

\section{Ethics approval and consent to participate}

The study protocol was approved by the ethics committee of Hainan hospital of Chinese PLA General Hospital, which waived the requirement to obtain informed consent from the subjects.

\section{Consent for publication}

Not applicable.

\section{Availability of data and materials}

The datasets generated and analyzed during the current study are available from the corresponding author on reasonable request.

\section{Competing interests}

We, the authors, declare that we have no competing interests.

\section{Funding}

This work was supported by Major Science and Technology Plan of Hainan Province (ZDKJ2016008) and the Natural Science Foundation of Hainan Province (20168359) for data collecting, manuscript editing and proofreading, and publication cost.

\section{Authors' contributions}


JJ.: Collecting data, drafting the manuscript, final approval of the manuscript. WT.: Collecting data, drafting the manuscript, final approval of the manuscript. WM.: Interpretation of data, revision of the work for important intellectual content, final approval. LYH.: Statistical consultations and manuscript review, final approval. All authors read and approved the final manuscript.

\section{Acknowledgements}

The authors would like to thank Medjaden Bioscience Limited that help editing and proofreading this manuscript.

\section{Contributor Information}

Jiao Jie, Email: jiaojie143@163.com

Wang Meng, Email: w2284153026@qq.com

Lei Yong-Hong, Email: jijiuke415@163.com

\section{Wang Tao, Email: 591698226@qq.com.}

\section{References}

1. Moskop J C, Sklar D P, Geiderman J M, et al. Emergency Department Crowding, Part 1-Concept, Causes, and Moral Consequences[J]. Annals of emergency medicine, 2009, 53(5):605-611.

2. Moskop J C, Sklar D P, Geiderman J M, et al. Emergency Department Crowding, Part 2-Barriers to Reform and Strategies to Overcome Them[J]. Annals of Emergency Medicine, 2009, 53(5):612-617.

3. Cooke M. Reducing Attendances and Waits in Emergency Departments: A Systematic Review of Present Innovations: Report to the National Co-ordinating Centre for NHS Service Delivery and Organisation R \& D (NCCSDO)[M]. NCCSDO, 2005.

4. Forero R, Mccarthy S, Hillman K. Access block and emergency department overcrowding[J]. Critical Care, 2011, 15(2):216.

5. Li Y, Li C, Xu J, et al. Emergency department enlargement in China: exciting or bothering[J]. J Thorac Dis, 2016, 8(5):842-847.

6. Wang Z, Xiong X, Wang S, et al. Causes of Emergency Department Overcrowding and Blockage of Access to Critical Services in Beijing: A 2-Year Study[J]. The Journal of Emergency Medicine, 2018: S0736467918301185.

7. Tong J, Zhu Y, Jie J, et al. Analysis of current situation of Chinese health care reform by studying emergency overcrowding in a typical Shanghai hospital[J]. American Journal of Emergency Medicine, 2012, 30(7).

8. Ye L, Zhou G, He X, et al. Prolonged length of stay in the emergency department in high-acuity patients at a Chinese tertiary hospital[J]. Emergency Medicine Australasia, 2012, aop(aop). 
9. Yutong L I, Yi Z. Study on Living Situation of "Seasonal Migratory Retirees"-Based on Survey in Hainan Province[J]. Population Journal, 2018.

10. Kou L, Xu H, Kwan M P. Seasonal mobility and well-being of older people: The case of 'Snowbirds' to Sanya, China[J]. Health \& Place, 2018, 54:155-163.

11. Emergency Severity Index (ESI): A Triage Tool for Emergency Department Care, Version 4. Implementation Handbook 2012 Edition. AHRQ Publication No. 12-0014. Rockville: Agency for Healthcare Research and Quality, 2011.

12. Lian-Rong Z, Bing L, Zhi-Qing P, et al. Effects of climate on chronic diseases in migrant elderly people in Hainan[J]. Hainan Medical Journal, 2018. Hainan Med J, Feb. 2018. Vol. 29, No. 3

13. Zhang Jing, Liu Jinglong, He Chao-Ming. Differences in motor function recovery in "migrant birds" stroke patients in Hainan [J]. Chinese Journal of Gerontology, 2016, 36:1084-1085. doi: 10. 3969 /j. issn. 1005-9202. 2016. 05. 028

14. Bing $L$, Zhiqing $P$, Jingbing $L$, et al. Cross-sectional study of influence of regional variations on migrant elder health status[J]. Chinese Journal of Health Care \& Medicine, 2017, 19(3).

15. Peng Y, Shen-Shen L I, Li-Xin X. Relationship of environment factors from satellite remote sensing and migratory bird-like elderly with chronic obstructive pulmonary diseases[J]. Chinese Journal of Multiple Organ Diseases in the Elderly, 2017, 16: 173-176.

16. Pu Hongwei, Chen Mo-Shui, Liu Wenjun, et al. Therapeutic effect of lowering blood pressure and related inflammatory factors and neurological deficit scores in elderly hypertensive patients in Hainan [J]. Chinese Journal of Gerontology, 2015, v.35(16):4512-4514.

17. Di Somma, S., Paladino, L., Vaughan, L. et al.Overcrowding in emergency department: an international issue[J]. Internal and Emergency Medicine, 2015, 10(2):171-175. https://doi.org/10.1007/s11739-014-1154-8

\section{Figures}




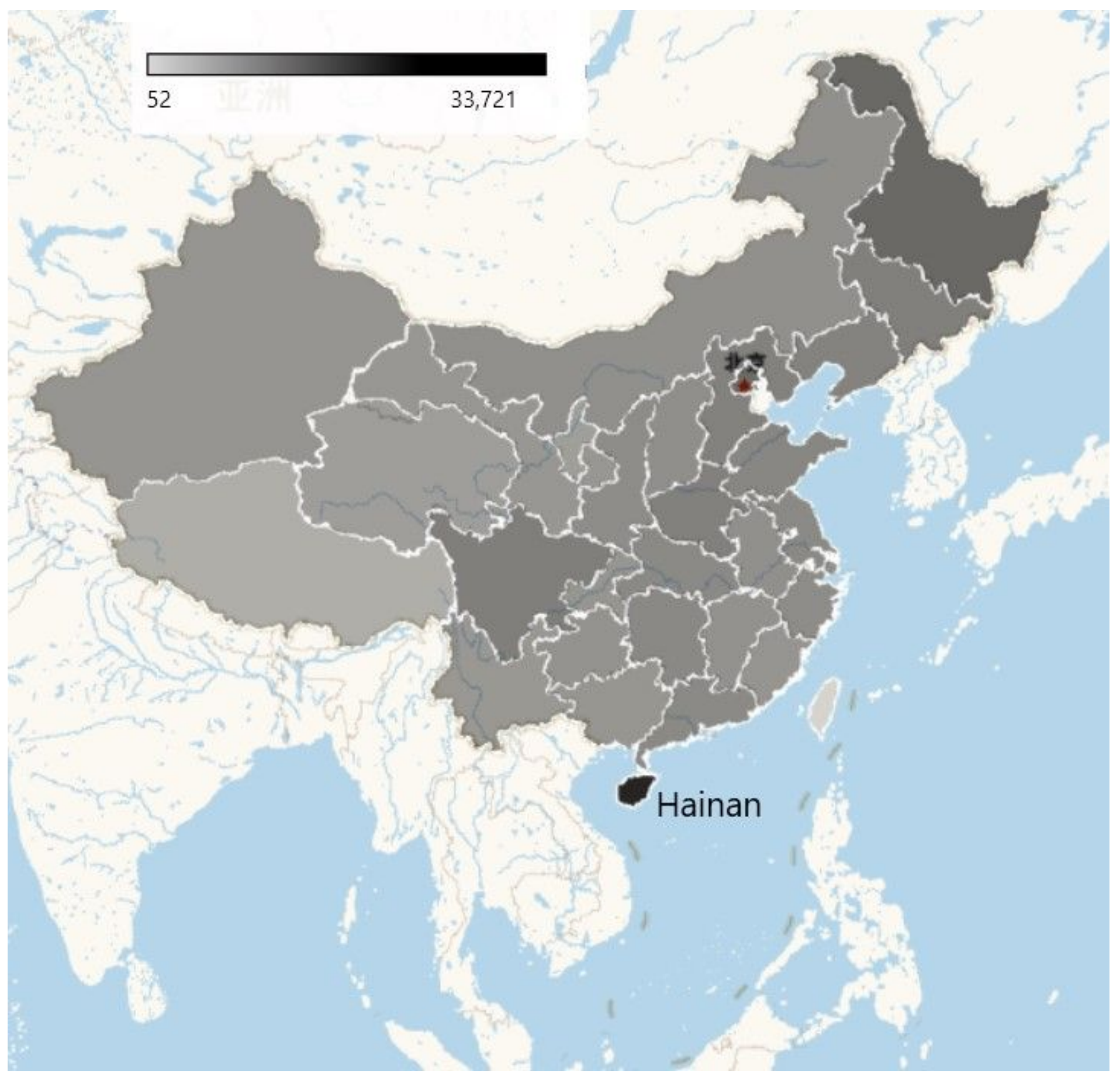

\section{Figure 1}

Geographic distribution of emergency department visitors by province in China. Note: The designations employed and the presentation of the material on this map do not imply the expression of any opinion whatsoever on the part of Research Square concerning the legal status of any country, territory, city or area or of its authorities, or concerning the delimitation of its frontiers or boundaries. This map has been provided by the authors. 


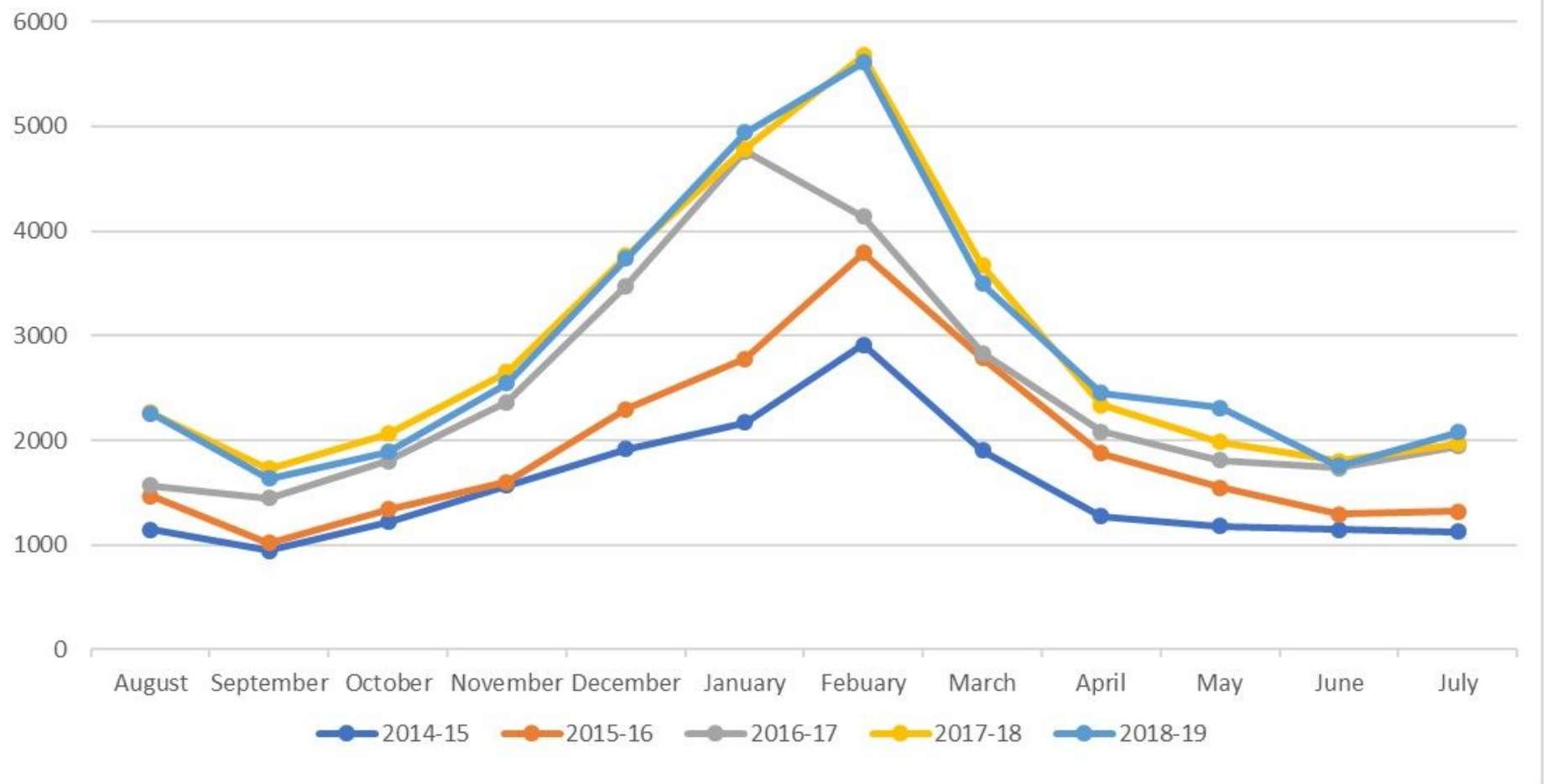

Figure 2

Number of emergency department visitors by month from 2014.08 to 2019.07 .

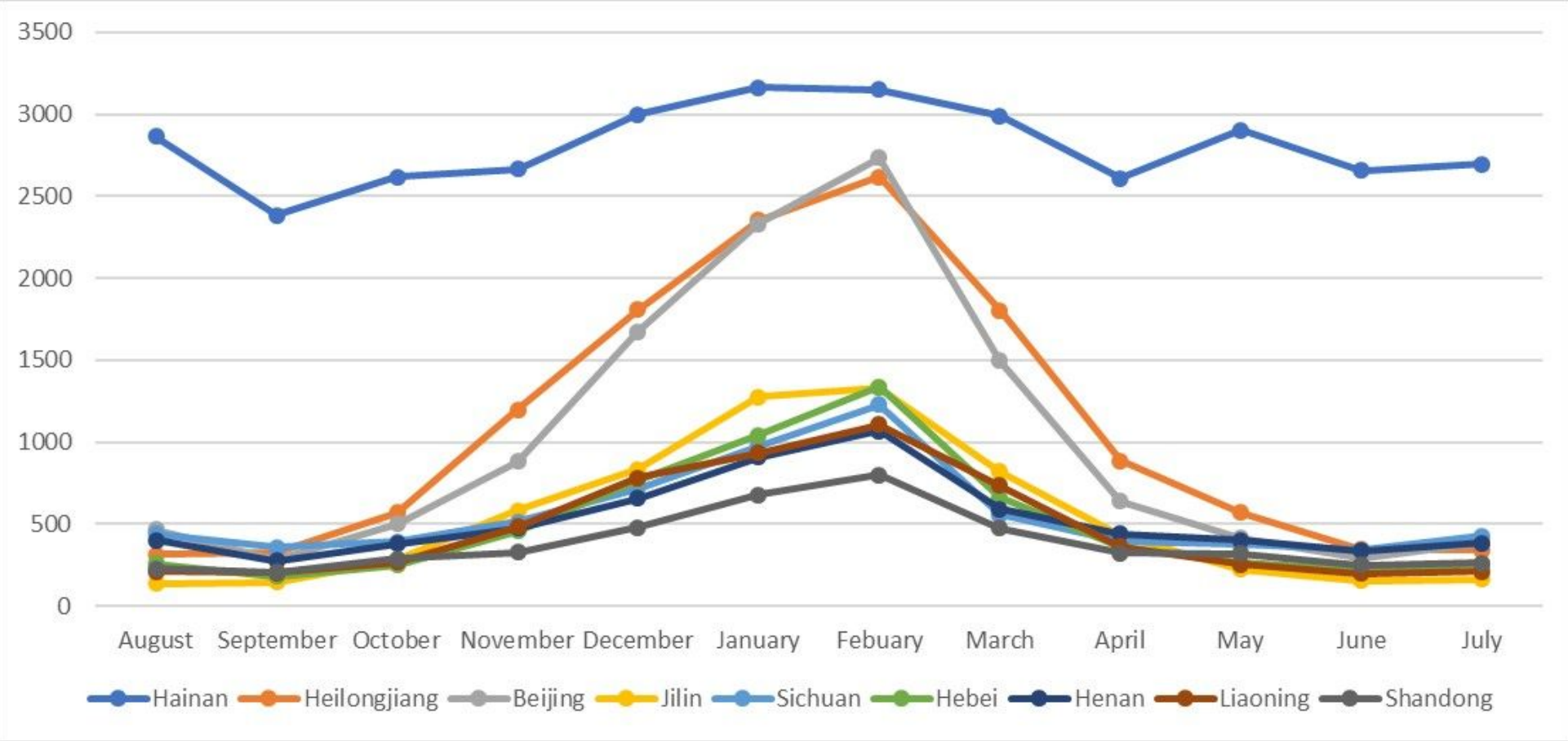

\section{Figure 3}

Number of emergency department visitors in major provinces in China by month in five-years interval from 2014.08 to 2019.07. 


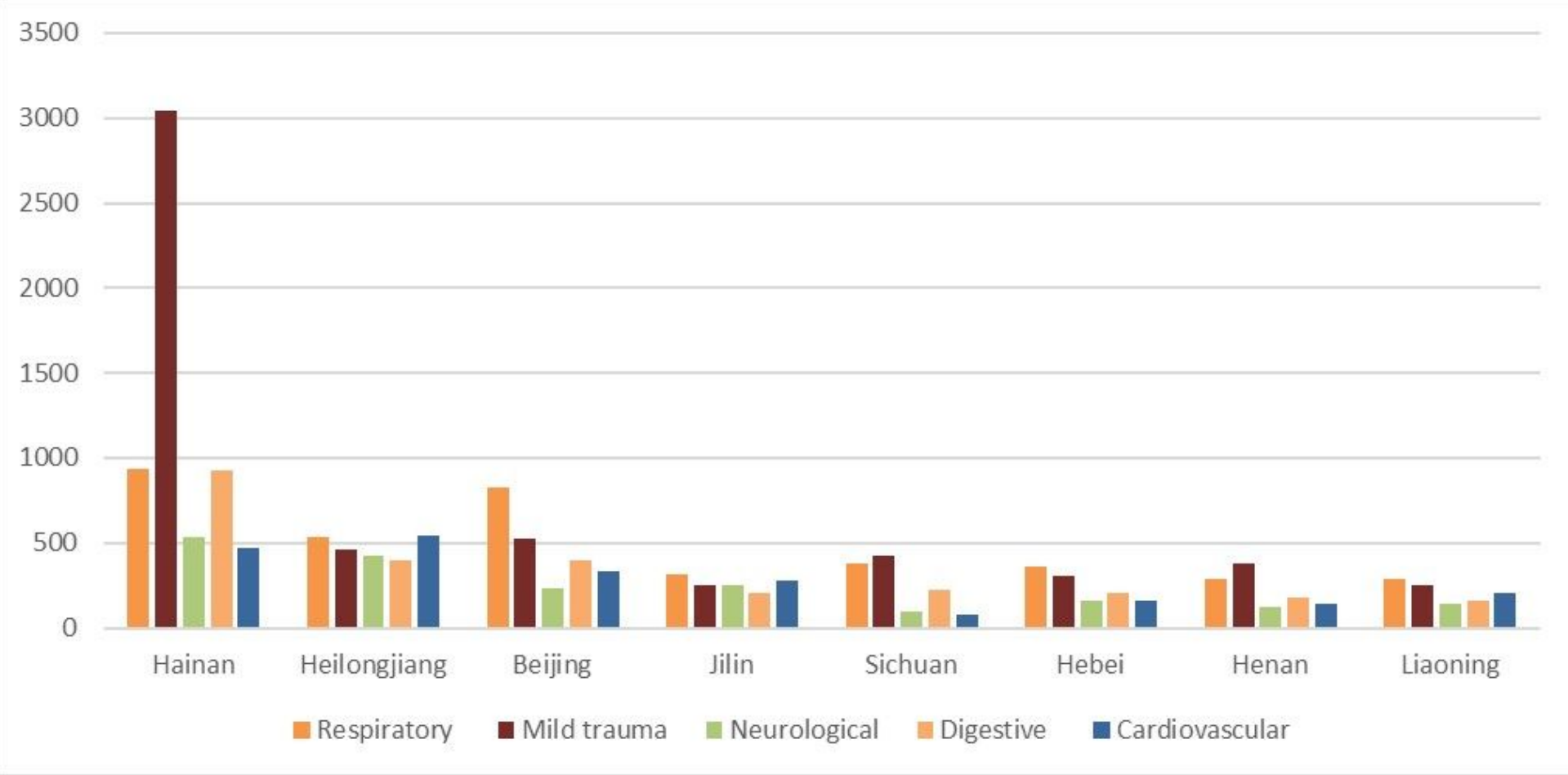

\section{Figure 4}

Disease categories by province in China in one-year interval from 2017.08 to 2018.07 ( $P<0.05$ using the chi-square test).

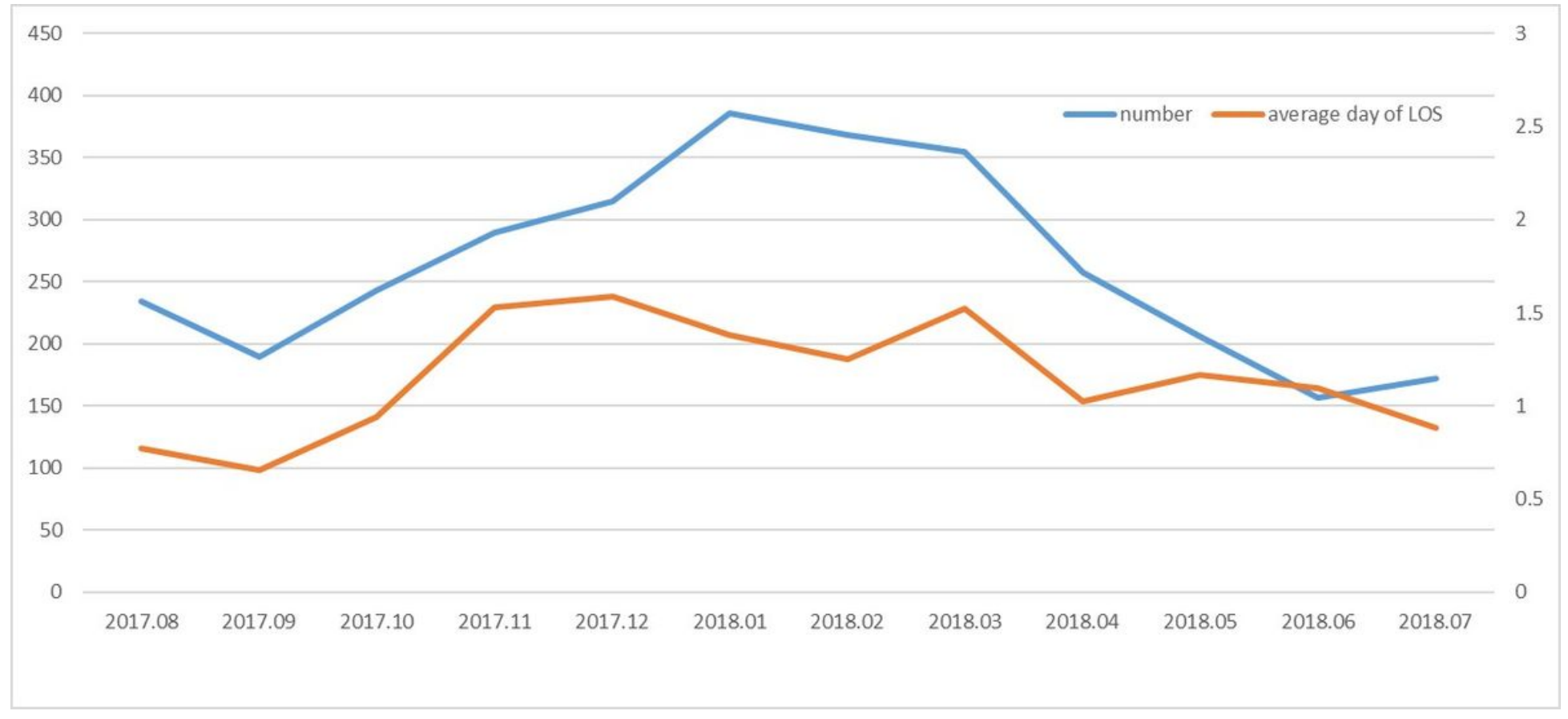

\section{Figure 5}

Number of patients staying in emergency department observation units and critical care units and the mean length of stay (days) by month from 2017.08 to 2018.07. 